Currículo sem Fronteiras, v. 19, n. 3, p. 1358-1378, set./dez. 2019

\title{
DAS INCERTEZAS ÀS CERTEZAS DA PESQUISA NÃO ARBITRÁRIA EM SALA DE AULA VIA METODOLOGIA DICUMBA
}

\author{
Everton Bedin \\ Universidade Luterana do Brasil - ULBRA \\ José Claudio Del Pino \\ Universidade Federal do Rio Grande do Sul - UFRGS
}

\begin{abstract}
Resumo
Neste artigo apresenta-se o desenvolvimento, a aplicação e a síntese de uma proposta de ensino intitulada Dicumba (Desenvolvimento Cognitivo Universal-bilateral da Aprendizagem), dando-se ênfase as considerações de 27 estudantes. A constituição de dados ocorreu por meio de 9 passos e, para autenticar e validar os dados, um questionário. Os dados foram analisados por meio da Análise Textual Discursiva e representados pelo programa Statistical Package for the Social Sciences for Windows. Constatou-se que a Dicumba desperta a motivação e o desejo de o estudante buscar aprender a aprender e ser autor da própria formação; logo, propõe-se que estudos e ações sobre esta metodologia sejam ampliadas e realizadas em outros contextos, e que o currículo da Educação Básica seja reestruturado a partir das questões histórico-políticas e socioculturais do aluno.
\end{abstract}

Palavras-chave: Metodologia Dicumba. Pesquisa em química. Aprendizagem centrada.

\begin{abstract}
In this paper we present the development, application and synthesis of a teaching proposal entitled Dicumba (Universal-Bilateral Cognitive Development of Learning), emphasizing the considerations of 27 students. The data collection took place through 9 steps and, to authenticate and validate the data, a questionnaire. The data were analyzed through Discursive Textual Analysis and represented by the Statistical Package for the Social Sciences for Windows program. It was verified that the Dicumba awakens the motivation and the desire of the student to learn to learning and to be the author of the formation yourself; therefore, it's proposed that studies and actions on this methodology be expanded and carried out in other contexts, and that the Basic Education curriculum is restructured from the student's historical-political and socio-cultural issues.
\end{abstract}

Keywords: Dicumba Methodology. Research in Chemistry. Student-centered learning. 


\section{Principais ideias}

A prática de instigar o aluno a pesquisar para aprender e ensinar de forma cooperativa tem ficado cada vez mais presente nas salas de aula da Educação Básica e nos cursos de licenciatura e pós-graduação da Educação Superior, uma vez que a relação entre a pesquisa, a formação docente e a qualificação dos processos de ensino e aprendizagem tem tomado a cena quanto aos debates e aos estudos vinculados à emersão de atividades que qualificam o ato de ensinar e a ação de aprender dos sujeitos à luz da formação científica. Além disto, a relação entre a pesquisa e o ensino e, principalmente, destes com o desenvolvimento de práticas pedagógicas tem embriagado de forma exacerbada as diferentes fontes da literatura que se vinculam a temática. Por exemplo, literaturas específicas e legislação sobre a formação docente passaram a admitir a importância da prática de pesquisar para planejar e desenvolver ações referentes ao trabalho docente (Lüdke, 2008).

Esta maximização que tem emergido na literatura quanto ao ato de pesquisar na formação inicial de professores é decorrência da ideia de que a pesquisa é um mecanismo fortíssimo para a construção e a reconstrução de conhecimentos, saberes e cultura (Demo, 2005; Ens, 2006). A pesquisa é um ato que fomenta as concepções de democratização explícitas da Educação Básica e da formação docente, uma vez que se caracteriza, em seus vieses educativos, como mecanismo de qualificação na formação do sujeito a partir da ação docente que "se propõe a formar cidadãos críticos, participativos, solidários, autônomos, responsáveis pela formação de homens e de mulheres e por sua autoformação" (Ens, 2006, p. 13).

Apesar de uma significativa apresentação de pesquisas literárias relativas ao ato de Educar pela Pesquisa no Brasil, Demo (2004) considera o estilo da literatura como hipotético e insatisfatório, dando-se ênfase a uma visão dicotomizada de ensino e pesquisa, manifestada na estrutura das propostas curriculares e nas conjeturas teórica-metodológicas, revelando um dos maiores problemas existentes na formação e na profissionalização docente: a lacuna entre teoria e prática e entre o fazer e o dizer pedagógico.

Corroborando quanto aos problemas enfrentados na formação docente no Brasil, Galiazzi e Moraes (2002, p. 251) advertem que "a formação de professores tem sido historicamente criticada pela incapacidade de estabelecer uma relação complementar entre teoria e prática”, aqui, ainda vinculamos, entre fazer e dizer, entre ensino e pesquisa e, porque não, entre formação e profissão. Para os autores, alguns problemas são derivados desde a origem, aludindo-se, exclusivamente, "à separação entre conteúdos disciplinares específicos e conteúdos pedagógicos; à falta de integração entre o conhecimento trabalhado na academia sobre a realidade prática e esta realidade" (Galiazzi; Moraes, 2002, p. 249).

Neste sentido, este artigo tem o objetivo de apresentar o desenvolvimento de uma atividade vinculada ao ato de Aprender pela Pesquisa, dando-se ênfase significativa a atividade desenvolvida e as considerações dos estudantes da Educação Básica a partir da pesquisa centrada no aluno; logo, entende-se que esta ação, por mais que se aproxime da ação do Educar pela Pesquisa, apresenta-se como uma nova estratégia de ensino, capaz de potencializar a aprendizagem do aluno a partir de temas relacionados ao seu interesse e 
vinculados a sua realidade que, após a pesquisa macro, são ressignificados aos saberes científicos advindo da ação docente.

Nesta perspectiva, este trabalho se justifica como ponto sumo para a qualificação dos processos de ensino e aprendizagem, assim como para a formação inicial e continuada de professores, uma vez que, além de apresentar de forma crítica e reflexiva uma atividade desenvolvida no berço da pesquisa, apresenta uma proposta que vincula a formação do sujeito a partir daquilo que lhe é interessante, aproximando-o da sala de aula, do ensinar, do aprender e do conteúdo científico radicado a sua vivência por meio da pesquisa de seu interesse e de sua curiosidade. Afinal, é importante "instigar o educando a pensar, analisar e fazer, por meio de seus conhecimentos, mudanças dinâmicas no mundo atual” (Bedin, 2015, p. 41).

Assim, acredita-se que a pesquisa aqui presente é mais uma estratégia para romper com a dicotomia existente entre a teoria e a prática à qualificação do ensino, valorizando: 1 - a união entre o dizer e o fazer docente (o professor passa a ser facilitador do processo de ensinagem); 2 - a conexão entre a prática de pesquisar e ensinar (o aluno aprende e ensina na medida em que pesquisa); 3 - a vinculação entre formação e profissionalização (o professor, mesmo diante de um sistema educacional maçante, coloca em prática seus aprendizados filosóficos, pedagógicos e epistemológicos da graduação) e 4 - a valorização do saber do aluno para o desenvolvimento de competências e habilidades relacionadas ao saber científico.

Nesta perspectiva, ao se refletir sobre a pesquisa, é sagaz pensar se esta pode estar presente na Educação Básica não apenas como arquétipo de resultados para o ensino, mas como um mecanismo de qualificação de práticas, conjugando sua realização empírica enquanto estrutura de respaldo aos interesses e atividades do aluno e na formação docente como parte integrante desta, para que o futuro professor possa tornar-se consciente do seu papel como pesquisador, no sentido de formar alunos com habilidades necessárias para enfrentar a complexidade e a diversidade das situações de vida pessoal e profissional que, cada vez mais, exigem criatividade, autonomia e pensamento crítico-reflexivo.

Neste sentido, é possível entender que a pesquisa no ensino não apenas no Ensino Superior como artefato da qualificação docente, onde se agrupa pela postura e pelas práticas de investigação e problematização, como destacado por Severino (2002), mas na Educação Básica, deveria perpassar em todas as áreas do saber, considerando que é um meio para constituir saberes, trocar informações e sistematizar conhecimentos. Neste desenho, Ens (2006, p. 13-14) enfatiza a articulação ensino e pesquisa, afirmando que esta pode contribuir com a formação de professores e, sobretudo, de alunos, instigando-os "na construção e (re)construção do conhecimento do contexto escolar e das interações que ocorrem nas salas de aula e no espaço da escola, elementos essenciais para a formação e autoformação do docente".

Apesar de Galiazzi e Moraes (2002, p. 243) explicitarem que o Educar pela Pesquisa proporciona qualidade política na formação docente, provocando o desencadeamento de "capacidades de intervenção qualificada nas realidades educativas, tanto em sentido restrito de sala de aula como no contexto mais amplo”, ajuíza-se a ideia de que o Aprender pela Pesquisa Centrada no Aluno (APCA), derivado da metodologia Dicumba (Desenvolvimento 
Cognitivo Universal-Bilateral da Aprendizagem), além de fortalecer a formação do professor, é uma forma prioritária de valorizar o interesse do aluno da Educação Básica e aguçar sua curiosidade por um tema, acerando sua capacidade individual e autônoma de construir e reconstruir argumentos críticos e coerentes com seu contexto sociocultural.

A concepção da metodologia Dicumba é, basicamente, fazer com que o educando pesquise algo do seu interesse e, a partir da pesquisa realizada por ele, o professor começar a traçar alguns fios norteadores do conhecimento científico para que o aluno possa, a partir de pesquisas mais sólidas e profundas, relacionando o saber social com o conhecimento científico, entender a relação dos saberes ao seu contexto. Ou seja, a Dicumba proporciona "ao aluno a conexão de sua vivência aos saberes do conteúdo de química e ao professor a percepção da necessidade de uma formação continuada para aperfeiçoar seus saberes docentes e o pleno conhecimento intradisciplinar” (Bedin; Del Pino, 2018b, 67).

Corroborando, Demo (2000, p. 24) entende a pesquisa como um viés educativo ao destacar que a mesma "quando bem entendida, sobretudo, pedagogicamente, serve para superar a imitação e promove estudantes questionadores/transgressores, quando professores também são questionadores”; logo, entende-se que o APCA faz com que o estudante passe por uma reconstrução, sendo esta elaborada por meio do pensamento crítico e exercitada pela ação da reflexão; o aluno se torna "produtor de conhecimentos e não só um repassador de informações. Por isso, é imprescindível a participação do profissional da educação em pesquisa, considerando que esse processo de formação envolve o "saber pensar criticamente" (Demo, 2000, p. 25).

Em virtude dos fatos, acredita-se que o APCA, tendo como base a metodologia Dicumba - criada em união pelos autores, tendo como motivação e princípio de emersão as angústias, as incertezas e os sentimentos envolvidos na construção de projetos de pesquisa lato (Especialização) e stricto sensu (Mestrado e Doutorado) realizados à luz do Ensino de Química na Educação Básica por um dos autores -, possa, além de tornar o aluno autônomo na construção e formação de seu aprendizado a partir da pesquisa centrada em seu contexto para, então, começar a entender, na ressignificação de conceitos e conteúdos, o saber científico, fortalecer o vínculo entre professor, aluno e conhecimento, pois este processo se configura em um pressuposto que traz ao aluno um domínio significativo sobre alguns conteúdos, os quais estão relacionados a fenômenos e conceitos próprios de sua vivência.

Assim, esta metodologia, ao ser desenvolvida em sala de aula, faz com que o aluno "desenvolva um espírito crítico-cientista por meio das atividades coletivas e dialógicas vinculadas à pesquisa de seu interesse, de sua curiosidade e, principalmente, de seu desejo" (Bedin; Del Pino, 2019, p. 6). De outra forma, Bedin e Del Pino (2019, p. 6) afirmam que a Dicumba é importante e relevante no fazer Educação porque "quando o aluno desenvolve uma pesquisa centrada naquilo que ele tem familiaridade e interesse, automaticamente, apresenta saberes sociais que serão considerados e aprimorados na medida em que a realiza”. Ou seja, para os autores, a Dicumba tem um caráter de pesquisa universal por possibilitar ao aluno realizar uma pesquisa sobre qualquer assunto, não necessariamente relacionado ao conteúdo de química; o aluno "é quem determina aquilo que irá pesquisar para, em seguida, o professor fazer conexões com o conteúdo científico, demonstrando a bilateralidade da 
pesquisa, a fim de que juntos possam aprender a aprender por meio da ressignificação de saberes” (Bedin; Del Pino, 2019, p. 6).

Nesta perspectiva, percebe-se que a metodologia Dicumba está diretamente relacionada à aprendizagem do aluno em sala de aula, pois, de acordo com Bedin e Del Pino (2018b, p. 69), o sujeito aprende por meio da pesquisa centrada em seu interesse, "extrapolando a ideia dicotomizada entre ensino e aprendizagem, proporcionando meios para que o mesmo seja o construtor de seu aprendizado e de sua história, vinculando-o cognitivamente à sua capacidade crítica e reflexiva”. Ou seja, o APCA, desenvolvido de forma não arbitrária e unidimensional, faz com que o estudante, na medida em que lê e busca respostas para resolver problemas, aprende com os próprios erros, aprende a aprender, faz e se refaz para ampliar seu acervo cognitivo (Bedin; Del Pino, 2018b).

Ademais, destaca-se que a pesquisa aqui descrita foi bem-sucedida nesta experiência, considerando as possibilidades e impossibilidades da mesma quanto ao tempo, o espaço, o grupo de alunos e a estrutura da escola e das aulas de Química no contexto em que foi desenvolvida. Portanto, é necessária sua aplicação em diferentes contextos para que seja possível avaliar, de forma mais geral, a sua aplicabilidade e sucesso. Afinal, é necessário entender que uma experiência bem-sucedida em um determinado contexto, a partir da metodologia Dicumba, pode não ter o mesmo resultado em outro contexto completamente distinto.

Ainda, como ajuízam Bedin e Del Pino (2018b, p. 69), é importante salientar que o APCA apresenta impossibilidades de desenvolvimento quando "os alunos, assim como os professores, não forem inseridos e constituídos ativamente neste processo, que exige diferentes habilidades e competências para mobilizar saberes em um repertório diferenciado de conhecimentos". Ou seja, neste desenho "podem ocorrer reações controvérsias, uma vez que a pesquisa exige, além do domínio do conhecimento e de saberes para filtrar as informações necessárias, paciência e aptidão para diagnosticar aquilo que é necessário dentro do passageiro” (Bedin; Del Pino, 2018b, p. 69).

\section{A pesquisa}

A atividade que aqui se relata fez parte da aplicação da metodologia Dicumba em uma turma da terceira série do Ensino Médio durante três meses. A proposta Dicumba foi selecionada por proporcionar ao estudante uma nova visão de ensino, instigando-o a aprender por meio daquilo que lhe é interessante, uma vez que o estudante escolhe uma temática, podendo não estar vinculada aos conteúdos científicos do professor, e, a partir desta ação, o professor faz pequenas ligações com o conteúdo científico, a fim de que o estudante consiga, no desenvolver de suas atividades do APCA, relacionar o conhecimento científico com o seu contexto, não ocorrendo o inverso (Bedin; Del Pino, 2018a,2018b); neste caso, quando o professor dirige a pesquisa para o aluno a partir de um tema por ele delineado, ocorre uma pesquisa arbitrária e linear. 
Basicamente, a proposta do APCA pode ser compreendida a partir de um pentagrama (símbolo da união e da síntese). Ao direcionar o olhar para a figura 1, é possível perceber as cinco principais ações que se entrelaçam na medida em que a Dicumba é desenvolvida.

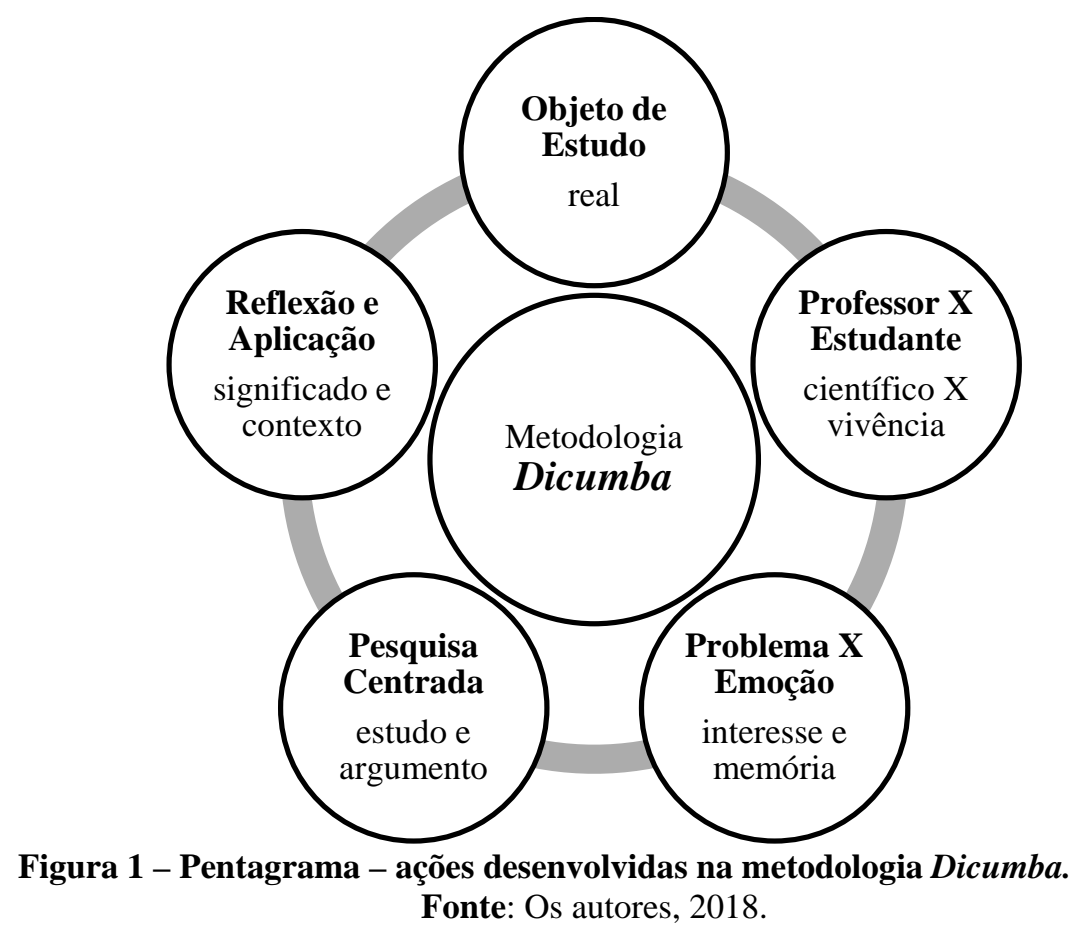

Assim, tem-se que este tipo de pesquisa pressupõe a relação entre os sujeitos envolvidos no processo de ensinagem de forma assídua, participativa e cooperativa, contemplando um objeto de estudo real que deriva da curiosidade do aluno a partir de sua realidade. Além do mais, por ser uma pesquisa centrada nos objetivos do aluno, os quais derivam particularmente de seus desejos e se relacionam com suas vivências, se desenvolve a partir da problematização do interesse deste e de suas emoções à luz da memorização, em meio a estudos e reflexões que levam a argumentação sobre o objeto estudado e ressignificado em seu contexto.

Assim, com o objetivo de fazer com que os estudantes se tornassem mais ativos, participativos e comprometidos com o processo de aprendizagem em sala de aula, propôs-se a estes que elencassem temas/assuntos de interesse, a fim de que desenvolvessem uma pesquisa individual para socializar em sala de aula. Esta atividade fez parte de um processo avaliativo do segundo trimestre do ano letivo de 2017 na disciplina de química, contando com a participação de 27 alunos (13 meninas e 14 meninos), da rede pública de ensino.

Para a realização da atividade, a qual foi coordenada pelo professor titular da disciplina, seguiu-se, consecutivamente: - escolha de um tema/assunto; - socialização do tema em sala de aula para a turma; - união de colegas por interesse de pesquisa; - realização de pesquisa por meio de diferentes tecnologias; - socialização das pesquisas em sala de aula; - 
direcionamento da pesquisa aos conteúdos de química geral pelo professor; - realização da pesquisa sobre o assunto com vistas aos direcionamentos realizados pelo professor; socialização das pesquisas realizadas e tira dúvidas com novos direcionamentos ao conteúdo de química; - apresentação final do trabalho.

Ao término da atividade, constatou-se a apresentação de 18 trabalhos, sendo realizados 3 trabalhos em trios, 3 trabalhos em duplas e 12 trabalhos individuais. Este passo foi primordial na pesquisa porque ao realizar uma pesquisa em conjunto, além dos educandos se constituírem a partir desta, a formação ocorre de forma dialogada e cooperativa por meio das interseções dos colegas. Assim, tem-se que a pesquisa cooperativa é fundamental para a formação e a aprendizagem a partir do outro, uma vez que a ação de pesquisar aquilo que é interessante e aprender a partir do convívio e da troca de saberes, relacionando-os ao científico e aos diferentes contextos, possibilita ao estudante construir consciência crítica e expressar conhecimento específico na construção e reconstrução de saberes e na produção de novos conhecimentos.

Para quantificar e qualificar a pesquisa, ao término de toda a atividade, o professor disponibilizou aos estudantes um questionário contendo 5 questões diretamente ligadas ao ato de pesquisar. O emprego desse instrumento de pesquisa justifica-se pela probabilidade de consentir o acesso a um número significativo de alunos, além de ser uma importante "técnica de investigação composta por um número mais ou menos elevado de questões apresentadas por escrito às pessoas, tendo por objetivo o conhecimento de opiniões, crenças, sentimentos, interesses, expectativas, situações vivenciadas etc” (Gil, 1999, p. 128).

Neste sentido, considerando as questões discursivas, os dados foram analisados por meio da Análise Textual Discursiva - ATD - (Moraes; Galiazzi, 2011, p. 7), pois essa “corresponde a uma metodologia de análise de dados e informações de natureza qualitativa com a finalidade de produzir novas compreensões sobre os fenômenos e discursos”. Além disto, este método de interpretação requer o envolvimento do pesquisador que, por sua vez, “precisa assumir-se intérprete e autor” (Moraes; Galiazzi, 2011, p. 10). Este processo de interpretar a escritura é organizado em três diferentes etapas: unitarização, categorização e produção de metatextos. Em especial, estes últimos, segundo Moraes (2003, p. 202), "são constituídos de descrição e interpretação, representando um modo de compreensão e teorização dos fenômenos investigados”.

Para o procedimento de unitarização, considerou-se as repostas dos alunos como unidades de sentidos diferenciadas, identificando-se e isolando-se as principais ideias com significados próprios. No processo de categorização, as unidades de sentido diferenciadas foram reunidas em categorias em função de justaposições e afinidades; é sagaz destacar que as categorias são produzidas de modo intuitivo a partir das escrituras analisadas, contribuindo para a organização do texto.

Assim, "as categorias constituem os elementos de organização do metatexto que se pretende escrever. É a partir delas que se produzirão as descrições e interpretações que comporão o exercício de expressar as novas compreensões possibilitadas pela análise" (Moraes; Galiazzi, 2011, p. 23). Por fim, a última etapa da ATD realizada foi a produção de metatextos, sendo representados como "um esforço de explicitar a compreensão que se 
apresenta como produto de uma nova combinação dos elementos construídos ao longo dos passos anteriores” (Moraes; Galiazzi, 2011, p. 12); logo, a partir da unitarização e da categorização, foi possível arquitetar a estrutura básica do metatexto, dando-se suporte teórico e ênfase crítica aos conteúdos das categorias.

Além disto, destaca-se que as questões objetivas apresentadas no questionário foram analisadas e interpretadas com base na ATD, mas, para o tratamento dos dados, buscou-se utilizar o programa Statistical Package for the Social Sciences (SPSS) for Windows, que possibilita a construção de tabelas com frequências e cruzamentos de dados.

\section{Resultados e discussão}

A tabela 1 demonstra os temas escolhidos pelos alunos, a justificativa apresentada por cada um referente aquilo que desejava pesquisar e a relação com o conteúdo de química direcionada pelo professor. Esta tabela é extensiva ao resultado apresentado pelos estudantes, uma vez que contempla de forma sucinta os 18 trabalhos realizados pela turma.

Tabela 1 - Síntese da metodologia Dicumba realizada pelos alunos.

\begin{tabular}{|c|c|c|c|}
\hline & Temas escolhidos & Justificativa & Relação com a química \\
\hline 1 & Esmalte & $\begin{array}{l}\text { É algo que uso muito, daí a importância } \\
\text { de entender sobre os riscos e benefícios. }\end{array}$ & $\begin{array}{l}\text { - composição e impactos da utilização nas } \\
\text { unhas. }\end{array}$ \\
\hline 2 & Bebidas alcoólicas & $\begin{array}{l}\text { Eu conheço um pouco e gostaria de } \\
\text { aprofundar meus conhecimentos. }\end{array}$ & - composição e processos de produção. \\
\hline 3 & Metanfetamina & $\begin{array}{l}\text { É uma droga viciante, em aspecto } \\
\text { cristalino, potente quanto a cocaína e o } \\
\text { crack. }\end{array}$ & $\begin{array}{l}\text { - grupos funcionais; - efeitos no cérebro; } \\
\text { - processo de produção. }\end{array}$ \\
\hline 4 & Futebol & $\begin{array}{l}\text { É um assunto que temos conhecimento; } \\
\text { somos de um time profissional. }\end{array}$ & $\begin{array}{l}\text { - tratamento de machucados físicos; - } \\
\text { produção de materiais esportivos. }\end{array}$ \\
\hline 5 & Perfume & Uso diariamente; me torna mais atraente. & - composição e processos de produção. \\
\hline 6 & Intolerante à lactose & $\begin{array}{l}\text { Sou intolerante a lactose e preciso } \\
\text { entender sobre o assunto. }\end{array}$ & $\begin{array}{l}\text { - lactose; grupos funcionais e degradação } \\
\text { do açúcar. }\end{array}$ \\
\hline 7 & Bomba atômica & É algo que aguça minha curiosidade. & - urânio; - explosão; - radioatividade. \\
\hline 8 & Depressão & $\begin{array}{l}\text { É algo que está sendo "moda" entre os } \\
\text { jovens, sendo problema social e familiar. }\end{array}$ & $\begin{array}{l}\text { - medicamentos; - efeitos químicos no } \\
\text { cérebro e princípios ativos. }\end{array}$ \\
\hline 9 & Plantas & $\begin{array}{l}\text { Faz parte do nosso dia, algumas são } \\
\text { frutíferas e outras apenas para } \\
\text { embelezamento. }\end{array}$ & $\begin{array}{l}\text { - toxicidade; - processos de evotranspiração } \\
\text { e fotossíntese. }\end{array}$ \\
\hline 10 & Acetona & $\begin{array}{l}\text { É um solvente que uso diariamente, pois } \\
\text { trabalho como manicure e pedicure. }\end{array}$ & $\begin{array}{l}\text { - composição e processo de remoção de } \\
\text { esmalte. }\end{array}$ \\
\hline 11 & Emoção & $\begin{array}{l}\text { Movem as ações humanas; a anatomia do } \\
\text { cérebro é linda. Sofro de depressão. }\end{array}$ & $\begin{array}{l}\text { - reações químicas do/no cérebro; } \\
\text { - neurotransmissor. }\end{array}$ \\
\hline 12 & Cosméticos & $\begin{array}{l}\text { Uso todo dia e não sei os efeitos a longo } \\
\text { prazo. }\end{array}$ & - composição e efeitos químicos na pele. \\
\hline 13 & $\begin{array}{l}\text { Pílula } \\
\text { anticoncepcional }\end{array}$ & $\begin{array}{l}\text { A utilidade diária me traz preocupações } \\
\text { sobre os efeitos. }\end{array}$ & $\begin{array}{l}\text { - composição; - grupos funcionais e efeitos } \\
\text { hormonais. }\end{array}$ \\
\hline
\end{tabular}




\begin{tabular}{|c|l|l|l|}
\hline 14 & Drogas & $\begin{array}{l}\text { É um dos grandes problemas que } \\
\text { vinculam minha comunidade e a escola. }\end{array}$ & $\begin{array}{l}\text { - tipos de drogas; - composição; - efeito no } \\
\text { cérebro e neurotransmissores. }\end{array}$ \\
\hline 15 & Vôlei & $\begin{array}{l}\text { Gosto do assunto, pois pratico de forma } \\
\text { profissional }\end{array}$ & $\begin{array}{l}\text { - material para a composição do spray para } \\
\text { dores; - hormônios ligados às emoções. }\end{array}$ \\
\hline 16 & Água & É vida e me importo com sua escassez. & - tratamento; - poluição; - consumo. \\
\hline 17 & Agroquímicos & Quero ser agrônomo. & - substâncias e diferentes classes e tipos. \\
\hline 18 & Álcool & $\begin{array}{l}\text { Algo do dia a dia, principalmente sendo } \\
\text { consumido por amigos e familiares. }\end{array}$ & - o que é; - utilização; - propriedades. \\
\hline
\end{tabular}

Fonte: os autores, 2018.

Observando-se a tabela, é possível perceber que vários temas não apresentam, em primeira instância, relação direta com o conteúdo de química, por exemplo, vôlei, emoção, depressão. Contudo, é possível perceber que, em meio a competências, habilidades e esquecendo a estruturação curricular determinada pelo sistema educacional, o professor consegue fazer relações diretas com o conteúdo, fazendo com que o estudante aprenda química a partir de algo de seu interesse. Assim, parece ser fundamental que o interesse e a curiosidade do aluno sejam considerados em sala de aula para, então, começar a desenvolver o conteúdo, não em uma sequência linear arquitetada pelo currículo, mas a partir daquilo que os sujeitos apresentam.

Em corroboração, Bedin e Del Pino (2018a, p. 345-346) entendem que o “Aprender pela Pesquisa propõe uma extrusão no currículo escolar, instigando o professor a pensar em novas maneiras de selecionar e organizar os conteúdos a partir da realidade sociocultural do aluno, contemplando a formação deste a partir do contexto em que está inserido”. Afinal, com a metodologia há "a primazia da qualidade da relação com o conhecimento sobre a quantidade de conteúdos apropriados de forma mecânica e, para além, supõe a anteposição do significado social do conhecimento sobre os critérios formais inerentes à lógica disciplinar” (BEDIN, 2015, p. 34). Ainda, é possível pensar que se o professor não tivesse se desvinculado do currículo, quiçá, estes saberes não teriam sido construídos nos alunos, uma vez que o docente “estaria centrado em um currículo fechado, que, geralmente, não apresenta conexões com as vivências dos alunos, buscando a constituição de ideias referentes a conhecimentos necessários para as avaliações, como exames e provas” (Bedin; Del Pino, 2018b, p. 80).

Nesta perspectiva, entende-se que questionar e instigar o aluno em sala de aula para que pense, investigue, crie hipóteses e argumente sobre algo são ações essenciais para qualificar a aprendizagem na Educação Básica, dando-se ênfase em um aspecto de aprendizagem reflexiva e crítica. Este desenho é importante, segundo Bedin e Del Pino (2019, p. 15), porque o aluno, "durante o processo de pesquisar a química relacionada ao tema de interesse, desenvolve habilidades de criticidade, argumentação e reconstrução de ideias, pois o processo exige do sujeito a mobilização de competências referentes ao ato de aprender”. Freire (1985, p. 46) corrobora afirmando que “[...] o que o professor deveria ensinar - porque ele próprio deveria sabê-lo - seria, antes de tudo, ensinar a perguntar. Porque o início do conhecimento, repito, é perguntar”; logo, o aluno que se instigar a pensar, refletir e 
problematizar sobre algo, conseguirá entender de forma satisfatória o conteúdo científico que se entrelaça àquilo que pesquisa.

A proposta de APCA se condiz com a concepção de um aluno autônomo e crítico, por meio da formação de um professor reflexivo, capaz de entender que o aluno faz parte de um processo de formação, sendo necessário constituir-se enquanto agente mobilizador das próprias competências; na perspectiva reflexiva de prática pedagógica é valorizado o saber do estudante como base para a própria formação (Lipman, 2014). Assim, tem-se que o APCA constitui-se em uma atividade necessária para a sala de aula da Educação Básica, pois, além de considerar o conhecimento prévio do estudante e aquilo que lhe é interessante para aprender, fortifica-se na medida em que o professor é visto como um facilitador da aprendizagem, sendo o estudante, dentro de processos de criticidade, raciocínio lógico, comunicação e mobilização de competências, parceiro do professor na busca de respostas aos seus próprios problemas/hipóteses.

Uma análise minuciosa por meio da ATD sobre as justificativas apresentadas pelos alunos faz emergir categorias que demonstram a importância de utilizar a Dicumba em sala de aula. Observe o SmartArt 1 que apresenta, em forma de palavras-chave, as categorias emergentes.

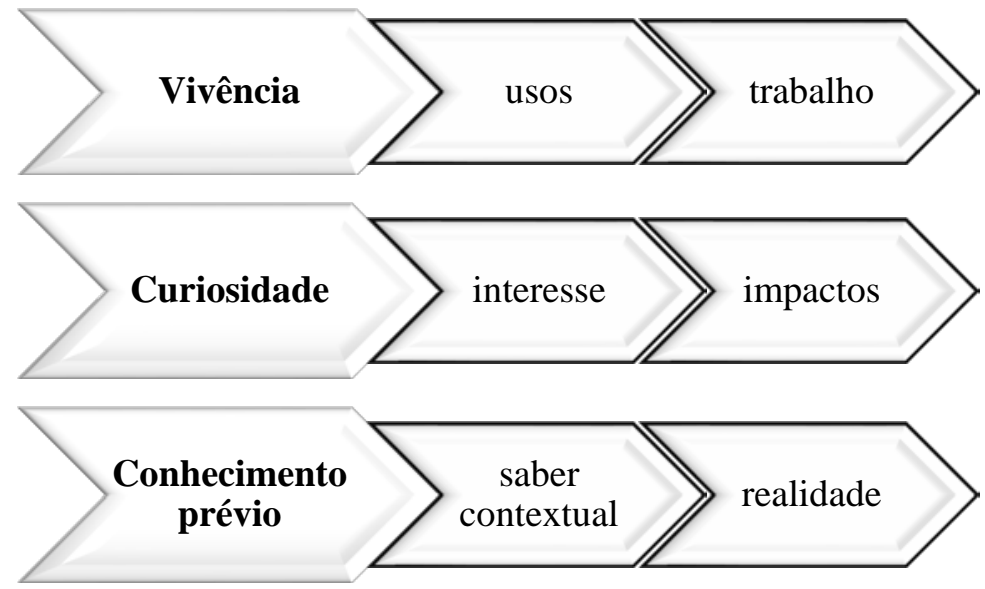

SmartArt 1 - Categorias emergidas da ATD sobre as justificativas dos alunos sobre a temática de interesse para a pesquisa na metodologia Dicumba

Fonte: Os autores, 2018.

Analisando-se as categorias presentes no SmartArt 1, percebe-se que a primeira delas é considerada a vivência do aluno, retomando-se as ideias de que estes têm satisfação para pesquisar e aprender sobre algo que usam e/ou que está diretamente relacionado ao seu trabalho. A segunda categoria refere-se à Curiosidade, dando-se ênfase a algo que desperta interesse ou que é pertinente aos envolvidos, daí a ideia dos impactos, por exemplo, do uso de drogas, álcool e pílulas anticoncepcionais. A última categoria refere-se aos conhecimentos 
prévios que os estudantes já possuem, sendo necessário o aprimoramento e a ressignificação do conhecimento científico ao seu contexto.

Estas categorias referem-se ao ato de o aluno relacionar um novo saber à proposições e conceitos relevantes em sua estrutura cognitiva para desenvolver a aprendizagem científica a partir de conhecimentos e/ou informações que já existiam com uma mínima noção de clareza, constância e caracterização. Assim, é necessário que o professor, enquanto facilitador da construção da aprendizagem, e por meio de seus diferentes materiais pedagógicos e práticas didáticas, consiga articular e ressignificar com competência os saberes científicos ao contexto sociocultural dos alunos. Afinal, para que a metodologia Dicumba tenha significância na aprendizagem do aluno, no sentido de instigar este à participação ativa e crítica, é preciso que haja, também, "participação ativa dos professores, incorporando saberes plenos e globalizados sobre a ciência química na pesquisa do aluno, transpassando o currículo e abrindo portas à imaginação e ao desejo daquilo que o aluno quer aprender" (Bedin; Del Pino, 2018a, p. 350).

De outra forma, segundo Bedin e Del Pino (2018b, p. 76), a metodologia Dicumba “exige que o professor apresente muito mais que conhecimentos intradisciplinares, mas que esteja ciente da necessidade de um planejamento", a fim de que perceba a necessidade de "uma formação continuada e qualificada nos saberes do conteúdo, de forma intradisciplinar, e nos saberes da didática, de forma universal” (p. 83). Ainda em relação a formação docente, Bedin e Del Pino (2019, p. 15), afirmam que:

[...] a metodologia instiga a necessidade de um aperfeiçoamento contextual dos saberes, pois quando o aluno estipula um tema de pesquisa que não está diretamente relacionado ao conteúdo de química, por exemplos, crianças e cachorro, o professor precisa pesquisar profundamente o tema para, então, pensar e relacioná-lo com o conteúdo de química; esta ação faz com que o professor busque uma formação continuada a partir de um tema macro da realidade do aluno.

Assim, acredita-se que a partir da pesquisa foi instigado o aluno a aprender de forma significativa, já que, para além de considerar algo de seu contexto, considerou-se aquilo que o estudante desejou para aprender. A Dicumba é um "posicionamento crítico no sentido de o aluno aprender ciências a partir daquilo que lhe é interessante e útil, caminhando para uma aprendizagem mais satisfatória e significativa” (Bedin; Del Pino, 2019, p. 16). Portanto, esta atividade, dentro de suas potencialidades, proporcionou aos estudantes significados que apresentaram componentes e afinidades pessoais, aperfeiçoando conhecimentos, construindo saberes e reconstruindo concepções e conceitos; "aprendizagem sem atribuição de significados, sem relação com o conhecimento pré-existente, é mecânica, não significativa. Na aprendizagem mecânica, o novo conhecimento é armazenado de maneira arbitrária e literal na mente do indivíduo" (Daher, 2017, s.p).

Para entender melhor os impactos da metodologia Dicumba utilizada pelo professor como artefato de pesquisa desenvolvida pelos estudantes, dentro do questionário, 
disponibilizou-se uma tabela que contemplava algumas assertivas e uma escala variante de +2 a -2, dando-se ênfase aos pressupostos de Likert (1932) em uma escala de cinco pontos, as quais, na visão de Brandalise (2005, p. 4), "requerem que os entrevistados indiquem seu grau de concordância ou discordância com declarações relativas à atitude que está sendo medida”. Analisando-se a tabela 2, é possível perceber, além das assertivas e da escala disponibilizada no questionário, as respostas dos alunos frente a cada assertiva.

É cogente destacar que, como foram realizados 18 trabalhos, para cada assertiva a soma de números nas escalas é igual a 18, variando conforme o grau de concordância dos alunos em relação as assertivas disponibilizadas.

Tabela 2 - Assertivas, escala de concordância e apontamentos dos alunos frente a utilização da metodologia Dicumba para APCA.

\begin{tabular}{|c|c|c|c|c|c|c|}
\hline & & \multirow{2}{*}{$\begin{array}{c}+2 \\
\text { Concordo } \\
\text { totalmente }\end{array}$} & \multirow{2}{*}{$\begin{array}{c}\mathbf{+ 1} \\
\begin{array}{l}\text { Concordo } \\
\text { em partes }\end{array}\end{array}$} & \multirow{2}{*}{$\begin{array}{c}\mathbf{0} \\
\text { Não } \\
\text { concordo e } \\
\text { nem } \\
\text { discordo }\end{array}$} & \multirow{2}{*}{$\begin{array}{c}\mathbf{- 1} \\
\text { Não } \\
\text { concordo } \\
\text { em partes }\end{array}$} & \multirow{2}{*}{$\begin{array}{c}-\mathbf{- 2} \\
\begin{array}{c}\text { Não } \\
\text { concordo } \\
\text { totalmente }\end{array}\end{array}$} \\
\hline & Assertivas & & & & & \\
\hline A & Fazer pesquisa me instiga a estudar & 11 & 7 & & & \\
\hline B & $\begin{array}{l}\text { A pesquisa me auxiliou a compreender } \\
\text { química }\end{array}$ & 9 & 9 & & & \\
\hline C & $\begin{array}{l}\text { Pesquisar algo do meu interesse para } \\
\text { aprender me instiga em aula }\end{array}$ & 16 & 1 & 1 & & \\
\hline D & $\begin{array}{l}\text { Aprender a partir do meu interesse é } \\
\text { importante }\end{array}$ & 15 & 2 & 1 & & \\
\hline $\mathbf{E}$ & $\begin{array}{l}\text { Há qualificação na minha aprendizagem } \\
\text { pela pesquisa centrada naquilo que me } \\
\text { interessa }\end{array}$ & 14 & 4 & & & \\
\hline $\mathbf{F}$ & $\begin{array}{l}\text { Com a pesquisa percebi a relação da } \\
\text { química com aquilo que me interessa, } \\
\text { ajudando-me a aprender }\end{array}$ & 11 & 5 & 2 & & \\
\hline G & $\begin{array}{l}\text { A pesquisa me instiga a ser autônomo e } \\
\text { crítico }\end{array}$ & 6 & 7 & 5 & & \\
\hline $\mathbf{H}$ & $\begin{array}{l}\text { O trabalho deixou-me mais ativo e crítico } \\
\text { sobre a química no meu contexto }\end{array}$ & 9 & 5 & 4 & & \\
\hline $\mathbf{I}$ & $\begin{array}{l}\text { O trabalho teve pouca validade, já que foi } \\
\text { árduo e trabalhoso }\end{array}$ & & & & 4 & 14 \\
\hline $\mathbf{J}$ & $\begin{array}{l}\text { O trabalho foi difícil e pouco interessante, } \\
\text { pois prefiro aula tradicional de quadro e } \\
\text { giz }\end{array}$ & & & & 1 & 17 \\
\hline $\mathbf{K}$ & $\begin{array}{l}\text { Pesquisar é algo que não me interessa, pois } \\
\text { não estrutura conhecimentos que julgo } \\
\text { necessários }\end{array}$ & & & 2 & & 16 \\
\hline $\mathbf{L}$ & $\begin{array}{l}\text { O trabalho trouxe competências a minha } \\
\text { formação }\end{array}$ & 11 & 7 & & & \\
\hline $\mathbf{M}$ & $\begin{array}{l}\text { O trabalho foi importante por me mostrar } \\
\text { que meu saber precisa ser aprimorado }\end{array}$ & 10 & 6 & 2 & & \\
\hline $\mathbf{N}$ & $\begin{array}{l}\text { O trabalho foi satisfatório porque com ele } \\
\text { consegui contextualizar a química na } \\
\text { minha vivência }\end{array}$ & 12 & 6 & & & \\
\hline
\end{tabular}

Fonte: Os autores, 2018. 
Da tabela 2, para facilitar a compreensão dos resultados, plotou-se o gráfico 1 que apresenta as assertivas em letras maiúsculas variando de A, sendo a primeira assertiva, a $\mathrm{N}$, como última assertiva. Observe o gráfico 1 para analisar o grau de concordância dos alunos.

Gráfico 1 - Gráfico referente a concordância dos alunos sobre a utilização da metodologia Dicumba.

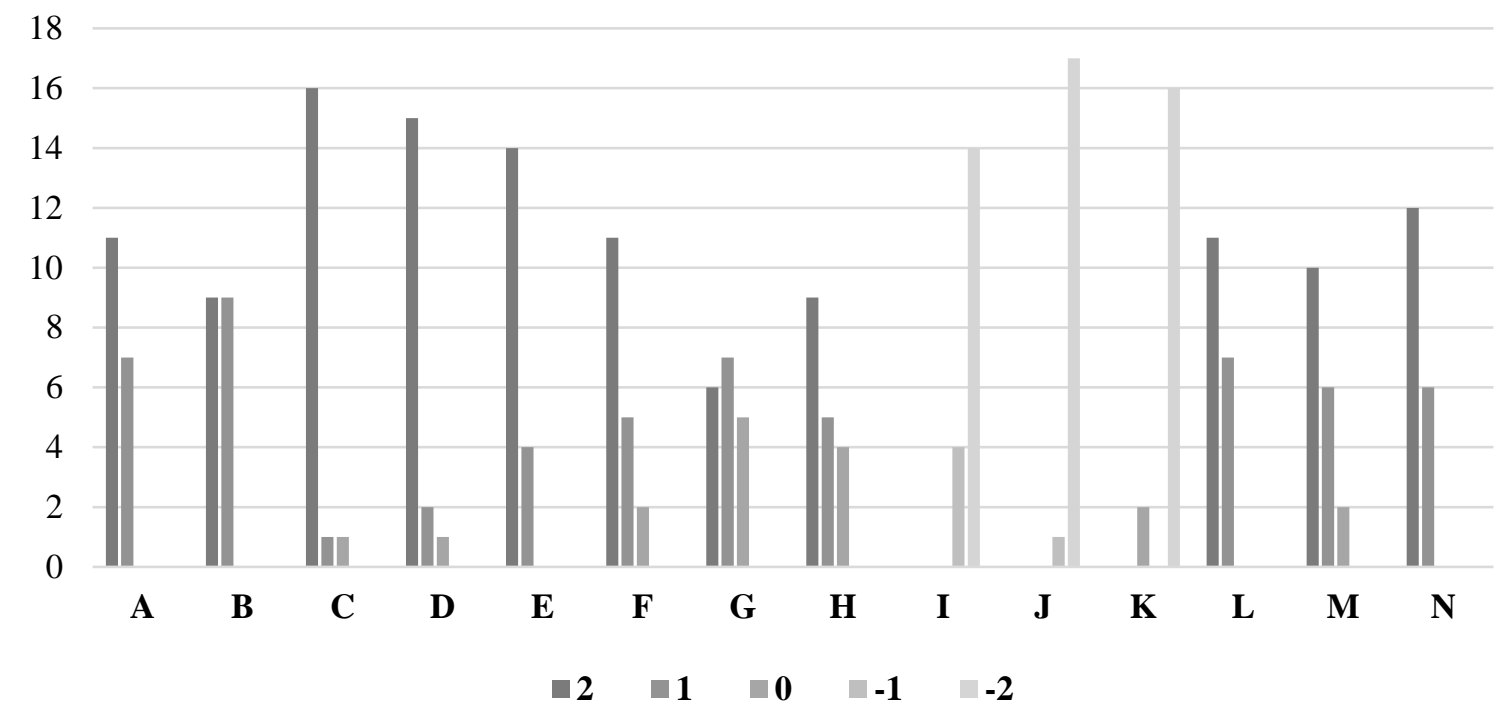

Fonte: Os autores, 2018.

Analisando-se o gráfico 1, pode-se perceber que os estudantes proliferam um grau de concordância significativo quanto a atividade desenvolvida, afirmando, em um percentual superior a 80\%, concordarem totalmente com as assertivas: pesquisar algo do meu interesse para aprender me instiga em aula; aprender a partir do meu interesse é importante e há qualificação na minha aprendizagem pela pesquisa centrada naquilo que me interessa. Da mesma forma, mas com um percentual entre $60 \%$ e $80 \%$ de aprovação, os alunos ajuízam que fazer pesquisa instiga-os a estudar; que com a pesquisa eles conseguem perceber a relação da química com aquilo que lhes é interessante, ajudando-os a aprender; que o trabalho trouxe competências a formação de cada um, mostrando-lhes que o próprio saber precisa ser aprimorado; e que com o trabalho eles conseguiram contextualizar a química na própria vivência.

Estes percentuais expressivos referentes a atividade desenvolvida demonstram que a aprendizagem no aluno ocorre de forma significativa quando este se sente instigado a pesquisar algo que lhe é afim, tornando-se autor dos mecanismos utilizados para aprender; logo, acredita-se que as ações de ensinar e aprender não podem ser vistas como precursoras da ação docente, visto que o sujeito aprende por meio de sua própria prática e não por meio do que se ensina. Ou seja, as ações de ensinar e aprender se conectam "em uma unidade dialética entre a instrução e a educação; ensinar e aprender; [...] a relação entre os processos 
de ensinar e aprender tem uma estrutura e um funcionamento sistêmico, isto é, está composto por elementos estreitamente inter-relacionados” (Bedin, 2015, p. 41).

Nesta esfera, Demo (2004, p. 60) compara a aprendizagem como um "processo dinâmico, complexo não linear, de teor autopoiético, hermenêutico, tipicamente interpretativo, fundado na condição de sujeito que participa desconstruindo e reconstruindo conhecimento". Ou seja, a atividade de APCA considera o ato de o aluno aprender como um problematizador, dando-se ênfase as questões dialéticas de desconstruir e reconstruir o conhecimento adquirido por meio da argumentação individual; o aluno aprende a partir daquilo que já sabe; há uma ressignificação do conhecimento contextual com base nos achados científicos.

Ainda sobre o gráfico, é necessário e importante afirmar que os alunos (90\%) discordam totalmente das assertivas: o trabalho foi difícil e pouco interessante, pois prefiro aula tradicional de quadro e giz e pesquisar é algo que não me interessa, pois não estrutura conhecimentos que julgo necessários. Assim, é possível perceber, a partir das colocações dos sujeitos, que a pesquisa por meio da metodologia Dicumba traz um novo conceito de desenvolvimento de ensino, arquitetando ideias de facilidade, interesse, curiosidade e estrutura de conhecimento centrada nos alunos.

Nesta perspectiva, é cabível destacar que a atividade desenvolvida pelo professor demonstrou a construção de uma postura investigativa e problematizadora no aluno, possibilitando a constituição e o desenvolvimento do senso crítico e de uma visão mais apropriada sobre os conteúdos científicos da ciência química presentes no contexto sociocultural investigado. Do mesmo, é possível perceber, a partir dos apresentados, que no ato de pesquisar houve a necessidade de uma reflexão crítica no aluno, assinalando uma atividade de investigação científica de caráter inovador e significativo.

Todavia, há de se destacar, apesar de ser um percentual baixo, os apontamentos que permaneceram no grau de não concordar e nem discordar de algumas assertivas. Neste sentido, acredita-se que o APCA traga dificuldades quanto aos conhecimentos básicos que os alunos apresentam em relação ao conteúdo, visto a necessidade de filtrar informações e reconhecer aquelas verdadeiras dentre as errôneas referentes ao assunto. Todavia, acreditase que isto seja um ponto relevante da Dicumba, pois faz com que o aluno perceba a necessidade de estar sempre buscando e atualizando-se frente ao vasto campo do conhecimento.

Lüdke e Cruz (2005), mesmo referindo-se a alunos da graduação, afirmam que as dificuldades encontradas na pesquisa se devem a vários fatores, principalmente quanto a falta de domínio de alguns conteúdos, ocasionando alguns equívocos pela presença de erros conceituais e conceitos distorcidos ou superficiais sobre o assunto. Ainda destacam problemas com a escrita e o "medo de errar, de expor seus conhecimentos considerados limitadores iniciais para o avanço na produção própria” (Lüdke; Cruz, 2005, p. 75).

Neste sentido, fez-se uma pergunta aberta aos alunos sobre as vantagens e as desvantagens em realizar a pesquisa por meio da metodologia Dicumba em sala de aula e relacioná-la com o conteúdo direcionado pelo professor. Afinal, é extremamente importante, após o desenvolvimento de uma atividade que foge do tradicional, que o professor busque 
compreender e entender sobre a aprovação ou não dos alunos, pois qualquer atividade pensada, desenvolvida e aplicada em sala de aula para qualificar os processos de ensino e aprendizagem está diretamente ligada ao estado emocional e cognitivo do aluno.

Para não dar prioridade de respostas e garantir a fidedignidade e a autenticidade do trabalho, optou-se em apresentar, por meio da tabela 3, as respostas apresentadas pelos alunos. Assim, a tabela apresenta três colunas, sendo a primeira relacionada ao tema escolhido (refere-se a tabela 1), a segunda sobre as vantagens apontadas pelos alunos e a terceira direcionada as desvantagens.

Tabela 3 - Vantagens e Desvantagens de trabalhar com a metodologia Dicumba em sala de aula a partir das concepções dos alunos.

\begin{tabular}{|c|c|c|}
\hline Temas & Vantagens & Desvantagens \\
\hline 1 & $\begin{array}{l}\text { Uma das principais vantagens foi entender a partir do meu } \\
\text { interesse os impactos dos esmaltes nas unhas, a presença de } \\
\text { formol na composição e a necessidade da unha se oxigenar. }\end{array}$ & Não identifiquei desvantagens. \\
\hline 2 & $\begin{array}{l}\text { A vantagem é que este tipo de pesquisa foi realizado a partir de } \\
\text { algo do meu interesse, não ficando maçante e despertando o } \\
\text { prazer em estudar. }\end{array}$ & Não tem desvantagem. \\
\hline 3 & $\begin{array}{l}\text { Realizar a pesquisa a partir de um assunto de livre escolha e } \\
\text { depois relacionar com o conteúdo me mostrou que a química da } \\
\text { sala de aula está presente em meu dia em todos os aspectos, } \\
\text { sendo necessário desempenho e aprofundamento para tornar-me } \\
\text { crítico. }\end{array}$ & $\begin{array}{l}\text { A desvantagem é que alguns colegas veem a } \\
\text { questão de liberdade de escolha como uma } \\
\text { forma de facilitar o trabalho, pesquisando } \\
\text { algo simples e sem interesse. }\end{array}$ \\
\hline 4 & $\begin{array}{l}\text { A vantagem é pesquisar algo que eu gosto e, por consequência, } \\
\text { acabo demonstrando mais interesse e dedicação. }\end{array}$ & Não encontrei desvantagens. \\
\hline 5 & $\begin{array}{l}\text { A vantagem é conhecer mais sobre aquilo que gosto, que me } \\
\text { interessa e que chama minha atenção. }\end{array}$ & Não há desvantagem. \\
\hline 6 & $\begin{array}{l}\text { Vantagem de entender o conteúdo de química a partir de algo } \\
\text { que eu pesquisei; trabalhar com algo do de meu interesse me faz } \\
\text { questionar ainda mais sobre as coisas, despertando a vontade de } \\
\text { querer saber além disso. }\end{array}$ & Não tem desvantagem. \\
\hline 7 & $\begin{array}{l}\text { Adquirir conhecimentos mais profundos sobre algo do meu } \\
\text { desejo e, depois, relacionar com a química que é fundamental } \\
\text { para o mundo. }\end{array}$ & Em branco. \\
\hline 8 & $\begin{array}{l}\text { A vantagem foi aprofundar o conhecimento sobre algo que } \\
\text { queríamos e, posterior, relacionar com a química da sala de aula } \\
\text { percebendo que existe química em tudo. }\end{array}$ & $\begin{array}{l}\text { Pouco saber sobre a química. Não entendia } \\
\text { muito a relação quando pesquisava, fazendo- } \\
\text { me pesquisar ainda mais. }\end{array}$ \\
\hline 9 & $\begin{array}{l}\text { A pesquisa nos mostrou como a química está presente nas } \\
\text { plantas e como estas são fundamentais para a nossa vida; a } \\
\text { pesquisa é vantajosa por relacionar o conteúdo de química com } \\
\text { algo que eu cobiço saber mais. }\end{array}$ & Não identificamos desvantagens. \\
\hline 10 & $\begin{array}{l}\text { É algo que sempre desejei aprender mais sobre, e relacionar com } \\
\text { o conteúdo de química é importante, pois não sabia sobre os } \\
\text { impactos da acetona e a composição química da mesma. }\end{array}$ & Creio que não há desvantagens. \\
\hline 11 & $\begin{array}{l}\text { O assunto, o conteúdo e a sala de aula se tornam mais atraentes, } \\
\text { pois é algo que eu gosto e tenho afinidade. }\end{array}$ & $\begin{array}{l}\text { Envolve mais tempo e eu preciso realizar as } \\
\text { atividades; o professor apenas orienta. }\end{array}$ \\
\hline
\end{tabular}




\begin{tabular}{|c|c|}
\hline 12 & $\begin{array}{l}\text { Esta pesquisa me proporcionou conhecimentos sobre o que } \\
\text { passo em minha pele, além de despertar maior interesse pelo } \\
\text { conteúdo de química e percebê-lo em meu dia a dia. }\end{array}$ \\
Adquirir novos e profundos conhecimentos sobre algo que eu \\
quero aprender, relacionando com compostos químicos e \\
conceitos científicos. \\
A pesquisa me ajudou a entender e descobrir novos conceitos \\
sobre o tema; relacionando com a química foi fundamental para \\
percebê-la em meu contexto e seus efeitos nas pessoas.
\end{tabular}

Não tem desvantagens.

Algumas informações errôneas presentes em sites diferentes.

Não há desvantagem.

Não identificamos desvantagens.

Descobrir como a água é tratada e alto índice de alumínio decorrente da coagulação.

Exigir atenção em relação as diferentes fontes de pesquisa; necessidade de leitura e interpretação de textos complexos.

Saber sobre os impactos negativos da utilização do álcool.

Fonte: Os autores, 2018.

Após interpretar a tabela 3, fez-se uma análise criteriosa por meio da ATD sobre as vantagens apresentadas pelos alunos, já que as desvantagens, ao serem analisadas de forma judiciosa, demonstram-se como vantagens do estudo, pois é necessário compreender todas as vertentes do tema, sejam elas positivas ou negativas. Além disso, identificar informações errôneas, compreender que o professor é apenas um orientador do processo de formação e construção de saber na Educação Básica, assim como haver a necessidade de ler, interpretar e disponibilizar maior tempo aos estudos, são ações que se configuram como mecanismos qualificadores da aprendizagem, fazendo com que o aluno se torne um agente mobilizador de suas próprias competências; o aprendizado é o maior objetivo para formar indivíduos transformadores.

Contudo, exclui-se a desvantagem: “alguns colegas veem a questão de liberdade de escolha como uma forma de facilitar o trabalho, pesquisando algo simples e sem interesse". Aqui, destaca-se a necessidade de uma argumentação crítica-reflexiva com os alunos em sala de aula, a fim de despertar nos mesmos a compreensão do papel da pesquisa, da aprendizagem e da autenticidade na formação, demonstrando que o importante na Educação Básica não é fazer, mas aprender a partir do aprender a fazer. Portanto, da tabela 3, plotouse o gráfico 2 que apresenta, em palavras-chave e número de vezes que estas se repetiram na unitarização dos dados, as principais categorias sobre as vantagens de utilizar a metodologia Dicumba em sala de aula.

Gráfico 2 - Categorias emergidas a partir da ATD sobre as vantagens de utilizar a metodologia Dicumba. 


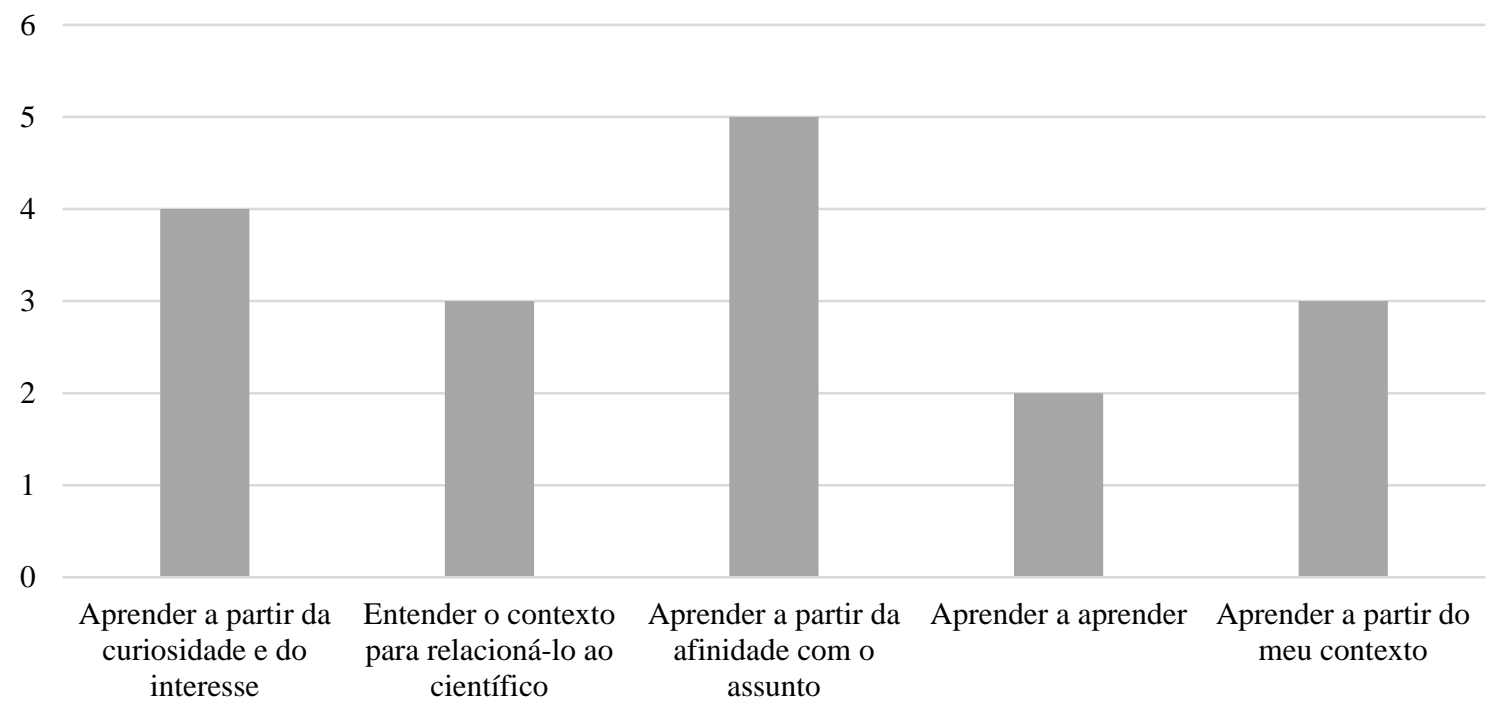

Fonte: Os autores, 2018.

Analisando-se o gráfico 2, pode perceber que a categoria “aprender a partir da afinidade com o assunto" é aquela que emerge com maior intensidade, já que a metodologia Dicumba se propõe a exatamente isso, fazer com que o aluno aprenda a partir daquilo que deseja/possui afinidade, compreendendo as diferentes maneiras de usar as ferramentas para mudar o mundo. Na sequência, tem-se a categoria “aprender a partir da curiosidade e do interesse”; esta categoria, diferente da anterior, não traz considerações de temas que o aluno tem afinidade ou gosto de pesquisar, mas a partir da curiosidade; ele tem curiosidade sobre algo que, não necessariamente, tenha afinidade.

Na sequência tem-se a categoria: "entender o contexto para relacionar o científico", a qual significa entender aquilo que está ao entorno do aluno para, então, começar a aprender os conceitos mínimos sobre o conteúdo de química, o que torna a metodologia inópia e extremamente importante, já que, em sua grande maioria, a literatura traz, exatamente, o contrário; o professor apresenta o conteúdo científico para começar a traçar relações com o contexto do aluno. Neste desenho, ainda se tem a categoria: "aprender a partir do contexto", referindo-se a ideia de estudar a partir daquilo que faz parte de sua vivência, instigando-o a ir além dos muros da escola para "aprender a aprender".

Ao entender o gráfico e compreender a emersão das categorias a partir da unitarização das escrituras dos alunos, é possível entender que, mais do que nunca, a educação e o processo de ensinagem se encaminham para um novo patamar; o professor deixa de ser detentor do saber e começar a ser um potencializador da aprendizagem, pois o aluno, por si só, deve ser capaz de buscar, filtrar e interpretar informações que sejam necessariamente significativas ao seu contexto e a sua vida.

Assim, acredita-se que chegou o momento de o professor proporcionar aos estudantes a capacidade de eles decidirem o que querem aprender e, a partir daí, fazer ligações com o conteúdo científico. É importante que a aprendizagem parta da realidade do aluno e deixe-o 
ser autor da própria formação; o professor passa a ser o mentor dos desejos do aluno e o orientador deste processo. Isto é, o professor deixa de ser transmissor de conteúdo e passa a ser o guia/coordenador do aluno para que este busque informações e processe-as em conhecimentos realmente necessários para o seu contexto e sua formação acadêmica.

De outra forma, Bedin e Del Pino (2019, p. 17) colocam que o professor, por meio da Dicumba, "passa a ser compreendido como um facilitador da aprendizagem, pois promove a conexão entre o científico e o contexto do aluno, estimulando-o a desenvolver autonomia e organização". Ainda, conforme os autores, "o estudante, por meio da pesquisa em sala de aula, adquire competências e habilidades cognitivas que farão parte de sua formação a partir da investigação sobre aquilo que julga ser importante para sua concepção, pois conhece a realidade em que fará uso e aplicação” (Bedin; Del Pino, 2019, p. 17).

Afinal, o aluno não precisa de um professor para receber informações que ele pode, facilmente, encontrar na Internet ou em outras fontes; o aluno precisa de um professor que mostre o científico presente naquilo que ele está pesquisando e apreendendo, a fim de que este possa enxergar problemas no mundo e, estimulado pelo APCA, sentir-se instigado e confiante a encontrar soluções. Afinal, o APCA é uma maneira de potencializar e maximizar “a aprendizagem do aluno de forma crítica, autônoma e reflexiva, despertando neste a curiosidade, a argumentação crítica e o interesse pela ciência” (Bedin; Del Pino, 2018a, p. 351).

\section{Considerações finais}

Ao término do texto, pode-se concluir que as inter-relações entre os contextos e os conceitos do conteúdo científico da disciplina de química encontradas nas pesquisas dos estudantes, a partir da análise de suas conjeturas apresentadas no questionário, expedem à possibilidade da construção da aprendizagem significativa no aluno a partir de sua ação, despontando de uma relevante variedade de vieses sociais possíveis à contextualização dos saberes e a valorização urgente dos interesses e das curiosidades múltiplas dos estudantes para a qualificação dos processos de ensino e aprendizagem.

Neste viés, acredita-se ser necessário pensar e refletir sobre a formação docente, pois se os professores em formação inicial não possuírem estruturas mínimas frente a esta metodologia de investigação-ação a partir do APCA, para a maximização do saber social e a ressignificação de conceitos e conteúdos químicos, é bem provável que o futuro da Educação Básica, em seus moldes de formação de caráter crítico-social, desenvolvimento de práticas pedagógicas e contextualização da vivência do aluno ao saber científico, permaneça da mesma forma em que se encontra hoje. Não se trata de um presente ruim que precisa, exacerbadamente, de mudanças significativas, mas o público-alvo de ontem é diferente do de hoje e, consequentemente, do de amanhã; logo, acredita-se que a metodologia Dicumba pode ser uma das diferentes estratégias de ensinar e aprender cooperativamente, interferindo na organização curricular do ensino Básico e Superior. 
Além do mais, como presente nos achados deste texto, é imprescindível que o APCA ganhe espaço e se torne uma estratégia de pesquisa na Educação Básica, pois, ainda hoje, busca-se o desenvolvimento dos conteúdos mínimos curriculares a partir do interesse do professor, valorizando a tomada de decisões e a compartimentalização do saber científico na medida em que se busca adequar às práticas pedagógicas e o trabalho docente aos princípios da objetividade e dos processos de seleção ao ensino superior, por exemplo, o Exame Nacional do Ensino Médio (ENEM) para vislumbrar o conhecimento científico.

Nesta perspectiva, é necessário pensar e refletir sobre os avanços da metodologia Dicumba em relação a outras metodologias de ensino produzidas no contexto do Ensino de Química. Isto é, por meio da discussão presente no texto, entende-se que metodologia Dicumba, a qual possibilita o APCA, possibilita ao aluno perceber e estudar química a partir do próprio contexto, "conjecturando-a como um constructo de vida presente em tudo aquilo que existe e coexiste com seu contexto, desenvolvendo conscientização reflexiva, argumentação crítica e desejo em desempenhar ações que sustentam a própria criatividade e curiosidade” (Bedin; Del Pino, 2018a, p. 350). Não obstante, o APCA, diferente de outras metodologias utilizadas no ensino de química, como demonstrado no texto, faz com que o sujeito se torne a própria aprendizagem, uma vez que conduze "as atividades em sala de aula e as ações de aprendizagem para a tomada de decisões de forma reflexiva e a emersão da argumentação crítica, fundamentando-se nos pressupostos epistemológicos de valores e condutas de um sujeito social, político e cultural” (Bedin; Del Pino, 1028b, p. 82).

Contudo, destaca-se a necessidade de os cursos de licenciatura e os professores titulares nas diferentes escolas buscarem por formação docente centrada e adequada de forma universal e contextualizada, pois o APCA requer um conhecimento mais amplo e complexo do professor, uma vez que, como demonstrado neste trabalho, alguns temas que os alunos cogitam pesquisar não estão, em primeira instância, relacionados diretamente com os conteúdos; daí deriva a necessidade de o professor ter amplo conhecimento do conteúdo e saber, a partir de suas competências e habilidades, relacioná-los de forma intradisciplinar, dando suporte relevante e eficiente as dificuldades que os alunos apresentam durante a pesquisa.

Finalmente, sugere-se que estudos e ações sobre o APCA sejam ampliadas e realizadas em outros contextos, de modo a valorizar o interesse e a curiosidade dos alunos para 0 desenvolvimento das atividades de ensino relacionadas ao conteúdo científico; a partir do saber do aluno desenvolve-se o saber científico, (re)aprimorando-se a partir da própria ação investigativa e problematizadora. Ainda, sugere-se pensar e refletir sobre a possibilidade de o currículo ser reestruturado a partir do contexto do aluno, dando-se ênfase às questões histórico-políticas e socioculturais para, então, pensar nos saberes científicos que devem ser desenvolvidos em sala de aula; o professor deve ser visto como mais um membro do processo de ensinagem e não como único e detentor do saber.

\section{Referências}


BEDIN, E. A emersão da interdisciplinaridade no ensino médio politécnico: relações que se estabelecem de forma colaborativa na qualificação dos processos de ensino e aprendizagem à luz das tecnologias de informação e comunicação. Tese (Doutorado em Educação em Ciências: Química da Vida e Saúde) Instituto de Ciências Básicas da Saúde, Universidade Federal do Rio Grande do Sul, Porto Alegre, 2015.

BEDIN, E.; DEL PINO, J. C. Dicumba: uma proposta metodológica de ensino a partir da pesquisa em sala de aula. Ensaio Pesquisa em Educação em Ciências (Belo Horizonte), v. 21, 2019. Disponível em: <http://dx.doi.org/10.1590/1983-21172019210103>. Acesso em: 09 set. 2019.

BEDIN, E.; DEL PINO, J. C. Dicumba - o aprender pela pesquisa em sala de aula: os saberes científicos de química no contexto sociocultural do aluno. Góndola, Enseñanza y Aprendizaje de las Ciencias, 13(2), 2018a, p. 338-352. Disponível em: <https://dialnet.unirioja.es/servlet/articulo?codigo=6750774>. Acesso em: 09 set. 2019.

BEDIN, E.; DEL PINO, J. C. A metodologia Dicumba como uma tempestade de possibilidades para o desenvolvimento do ensino de Química. Revista Brasileira De Ensino De Ciências E Matemática, Passo Fundo, v. 1, n. 1, p. 65-84, jan./jun. 2018. Disponível em: <http://seer.upf.br/index.php/rbecm/article/view/8479/pdf>. Acesso em: 08 de set. 2019.

BRANDALISE, L. Modelos de mediação de percepção e comportamento: uma revisão. 2005. Disponível em: <http://www.lgti.ufsc.br/brandalise.pdf\&gt>. Acesso em: 05 jun. 2018.

DAHER, A. F. B. Aluno e professor: protagonistas do processo de aprendizagem, 2017. Disponível em: $<$ https://www.campogrande.ms.gov.br/semed/wpcontent/uploads/sites/5/2017/03/817alunoeprofessor.pdf>. Acesso em: 04 jun. 2018.

DEMO, P. Conhecer e aprender: sabedoria dos limites e desafios. Porto Alegre: Artmed, 2000.

DEMO, P. Aprendizagem no Brasil: ainda muito por fazer. Porto Alegre: Mediação, 2004.

DEMO, P. Educar pela pesquisa. 7. ed. Campinas: Autores Associados, 2005.

ENS, R. T. Significados da pesquisa segundo alunos e professores de um curso de pedagogia. Tese (Doutorado em Educação: Psicologia da Educação) - Pontifícia Universidade Católica de São Paulo, São Paulo, 2006.

FREIRE, P. Por uma pedagogia da pergunta. Rio de Janeiro: Paz e Terra, 1985.

GALIAZZI, M. C.; MORAES, R. Educação pela pesquisa como modo, tempo e espaço de qualificação da formação de professores de ciências. Ciênc. \& Educ. Bauru, v.8, n.2, 2002. Disponível em: $<$ http://www.scielo.br/pdf/ciedu/v8n2/08.pdf>. Acesso em: 03 jun. 2018.

GIL, A. C. Métodos e técnicas de pesquisa social. 5. ed. São Paulo: Atlas, 1999.

LIKERT, R. A technique for the measurement of attitudes. Archives of Psychology, 22(140), 1932, p. 1-55. Disponível em: <http://psycnet.apa.org/record/1933-01885-001>. Acesso em: 20 dez. 2017.

LIPMAN, M. Pensamiento complejo y educación. Madrid: Ediciones de La Torre, 2014.

LÜDKE, M. A pesquisa do professor e a construção do conhecimento em didática. In: XIV ENDIPE - Encontro Nacional de Didática e Práticas de Ensino, 2008, p. 500-516. Disponível em: $<$ http://endipe.pro.br/2012/historico.html>. Acesso em: 10 jun. 2018.

LÜDKE, M.; CRUZ, G. B. Aproximando universidade e escola de educação básica pela pesquisa. Cadernos de Pesquisa, São Paulo, v. 35, n. 125, p. 81-109, maio/ago. 2005. Disponível em: < http://www2.fe.usp.br/ gpef/teses/grupo_01.pdf>. Acesso em: 15 dez. 2017.

MORAES, R. Uma tempestade de luz: a compreensão possibilitada pela análise textual discursiva. Ciência \& Educação, v.9, n. 2, p.191-211, 2003. Disponível em: <http://www.scielo.br/pdf/ciedu/v9n2/04.pdf>. Acesso em: 15 jun. 2018.

MORAES, R.; GALIAZZI, M. C. Análise textual discursiva. Ed. Unijuí, 2011.

SEVERINO, A. J. Metodologia do trabalho científico. 22. ed. São Paulo: Cortez, 2002. 


\section{Correspondência}

Everton Bedin - Doutor em Educação em Ciências pela Universidade Federal do Rio Grande do Sul (UFRGS); Mestre em Educação Química pela Universidade Federal de Uberlândia (UFU); Especialista em Gestão Educacional pela Universidade Federal de Santa Maria (UFSM) e em Tecnologias da Informação e Comunicação pela Universidade Federal do Rio Grande (FURG); Licenciado em Química pela Universidade de Passo Fundo (UPF). Professor Adjunto do Curso de Química e do Programa de PósGraduação em Ensino de Ciências e Matemática (PPGECIM) da Universidade Luterana do Brasil (ULBRA).

E-mail: bedin.everton@gmail.com

José Claudio Del Pino - Doutor em Engenharia de Biomassa e Mestre em Ciências Biológicas-Bioquímica pela Universidade Federal do Rio Grande do Sul (UFRGS); Especialista em Química pela Universidade de Passo Fundo (UPF) e em Ensino de Química pela Universidade de Caxias do Sul (UCS); Licenciado e Bacharel em Química pela Pontifícia Universidade Católica do Rio Grande do Sul (PUCRS). Professor associado e Professor-Orientador do PPG Educação em Ciência Química da Vida e Saúde e do PPG Química ambos da UFRGS. Bolsa de Produtividade em Pesquisa do Conselho Nacional de Desenvolvimento Científico e Tecnológico (CNPq).

E-mail: delpinojc@yahoo.com.br

Texto publicado em Currículo sem Fronteiras com autorização dos autores 